\title{
GAS PERMEATION CHARACTERISTICS ACROSS NANO-POROUS INORGANIC MEMBRANES
}

\author{
M.R OthMAN*, H. MUKHTAR AND A.L. AHMAD \\ School of Chemical Engineering, Engineering Campus, University Science Malaysia, 14300 \\ Nibong Tebal, P. Pinang. \\ Program of Chemical Engineering, University Technology Petronas, 31750 Tronoh, Perak \\ *e-mail: chroslee@eng.usm.my
}

\begin{abstract}
An overview of parameters affecting gas permeation in inorganic membranes is presented. These factors include membrane physical characteristics, operational parameters and gas molecular characteristics. The membrane physical characteristics include membrane materials and surface area, porosity, pore size and pore size distribution and membrane morphology. The operational parameters include feed flow rate and concentration, stage cut, temperature and pressure. The gas molecular characteristics include gas molecular weight, diameter, critical temperature, critical pressure, Lennard-Jones parameters and diffusion volumes. The current techniques of material characterization may require complementary method in describing microscopic heterogeneity of the porous ceramic media. The method to be incorporated in the future will be to apply a stochastic model and/or fractal dimension.
\end{abstract}

Keywords: Inorganic membrane, surface adsorption, Knudsen diffusion, Micro-porous membrane, permeation, gas separation.

\section{INTRODUCTION}

The separation of mixtures of gases is a common and important unit operation in chemical industries especially natural gas processing plant. Polymeric membranes have been used commercially for the separation of acid gases such as $\mathrm{CO}_{2}$ and $\mathrm{H}_{2} \mathrm{~S}$ from natural gas since 1979. However, polymeric membranes have several limitations attributable to low thermal and pressure resistant which hinder the use of such membranes for gas separation at high temperature. Gas separation involving relatively high temperature and/or pressure needs inorganic material membranes because polymeric membranes are not suitable at high temperature due to its thermal stability and resistant. The use of inorganic membranes for separation application has gained popularity in academia as well as industries due to inherent stability in extreme operating conditions. Apart from stability at high temperature and large pressure gradient, inorganic membranes are also known to be invulnerable to chemical attack from chemically active mixture and microbial degradation [1]. These favorable attributes have been identified to have brought about an increasingly improved acceptance level of inorganic membranes by industries. The fact that the service life of inorganic membranes is three to five times longer than their organic 
adversaries has fostered and rekindled even more interest among researchers in enhancing the state of the art of the present inorganic material characterization [11].

Inorganic membranes, commonly made from ceramic, sintered metal or metal oxide $\left(\mathrm{Al}_{2} \mathrm{O}_{3}, \mathrm{ZrO}_{2}\right.$, or $\left.\mathrm{TiO}_{2}\right)$, zeolite, palladium metal, glass tubes and pyrolyzed carbon have been gaining attraction particularly for application in a laboratory scale experiment [11]. Inorganic membranes can be tailored made to form a hybrid, asymmetric or composite membrane by means of sol-gel techniques or chemical vapor deposition [2].

Due to the imposing efficacies as illustrated in many technical journals and reports, the use of inorganic membranes for air filtration or air cleaning from particulate matters has been made more prevalent today than in the past. They have been used in replacement of a conventional filter such as dead-end fabric for clean room applications. They also have made a successful entry into the market as in line gas filters in microelectronic packaging, food and pharmaceutical industries to remove fine particles from gas streams $[2,11,20$, 29].

A more promising application with which inorganic membranes have received considerable attention in a wide array of industrial operations is gas permeation. This is particularly important in fuel cell application in which $\mathrm{H}_{2}$ and $\mathrm{O}_{2}$ are use as feed gas and the membrane acts as solid electrolyte in order to generate electricity [3]. Gas permeation involves feeding of gas mixture usually at a higher pressure or concentration into feed stream. Lower molecular weight gas species is separated from higher molecular weight gas species by virtue of different rate of diffusion through the membrane. Lower molecular weight species, having higher rate of diffusion will diffuse faster into a much lower pressure or concentration in the permeate stream of the membrane. The permeate stream, enriched with low molecular weight species is carried or driven by inert gas for further process or collection [4].

Few instances of gas permeation applications using inorganic membrane include separation of $\mathrm{CO}_{2}$ or $\mathrm{H}_{2}$ from methane and other hydrocarbons, adjustment of $\mathrm{H}_{2} / \mathrm{CO}$ ratio in syngas, separation of air into nitrogen and oxygen, recovery of helium and methane from bio-gas. Inorganic membranes also offer profound potential in applications for gas separation in a high temperature catalytic reaction and are potentially useful for the separation of trace contaminants such as ammonia, hydrogen sulfide and carbonyl sulfide from coal-gasifier fuel gases [5].

Permeation of gas species in porous inorganic membrane of average pore size less than $2 \mathrm{~nm}$ is contributed primarily by two internal transport mechanisms. The first being, Knudsen diffusion mechanism represented by the second term of Eq. (1), is prevailed in most of the porous systems where collision frequency between molecules and the pore wall increases. Mechanistically, the mean free path of the gas molecules before collision occurs is larger than the pore diameter of the membrane. The second mechanism is surface diffusion represented by the third term of Eq. (1), contributed primarily by the affinity of gas molecules adsorbed and diffused along the pore wall. The contribution of surface diffusion, however, is claimed to be significant only in a process operated at low temperature and high pressure region $[6,7,8]$. Minimal or insignificant effect was observed for high temperature process [9]. For a membrane having pore radius $\left(r_{p}\right)$ greater or equal 
to the molecular radius of gas species $i,\left(r_{g i}\right)$, the gas permeation can be described mathematically by,

$$
K=\frac{\varepsilon}{z \tau R T}\left\{\frac{\overline{\mathrm{P}} r_{p}^{2}}{8 \mu}+\left[\frac{2\left(r_{p}-r_{g}\right)}{3} \sqrt{\frac{8 R T}{\pi M}}+\frac{1}{\varepsilon}\left(D_{s} \rho_{m} f\right]\right\}, \text { where } \mathrm{r}_{\mathrm{p}} \geq \mathrm{r}_{\mathrm{g}}\right.
$$

and the ideal selectivity or separation factor, $\alpha$ is defined as the ratio of the permeability of the more diffusive gas to the less diffusive gas. In a binary gas mixture, the observed separation factor can be obtained experimentally using,

$$
\alpha=\left(\frac{y}{1-y}\right)\left(\frac{1-x}{x}\right)
$$

where $y$ and $x$ represent the mole fractions of the gas component in downstream and upstream of the membrane, respectively.

Despite the usefulness and the advantages inorganic membranes have had to offer, they are not without drawbacks especially with respect to selectivity, and the dilemma associated with pore size reduction. Extremely small pore size often reduces the permeability of the membrane [10], but high permeability is required for high flux of gas, whereas small pore size is desired for high degree of selectivity. In both cases, the success of separation process largely depends on many of the variables which range from the membrane's physical-chemical characteristics, operational parameters of the process to gas molecular characteristics in which, the combined effect of the diffusive properties of the gas species and the characteristics medium works to cause the desired level of separation of the gas.

Various factors affecting permeation of gas across inorganic membranes have been recognized in many recent scientific publications [1-32]. They are however, very much eclectic in nature whose results, some of which, pose challenges to researchers who are making effort at arriving and standardizing research conclusion. The objective of this paper is to briefly overview the crucial factors that characterize nano-porous inorganic membrane from past and present literatures based on such factors as membrane physical characteristics, operational parameters and gas molecular characteristics. The performance of gas separation in a system comprising $\mathrm{H}_{2}$ in a binary gas mixture is provided in the discussion. Anticipation on new methods of characterization of inorganic membranes in the future research setting is also included.

\section{PHYSICAL CHARACTERISTICS OF MEMBRANE}

Membranes formulated from different synthesis or techniques would result in membranes having different physical characteristics. Nevertheless, the fundamental parameters of interest to researchers for further inference about their characterization are noted as follows: 


\subsection{Membrane Materials and Surface Area}

Material selection and knowledge of physical adsorption of a gas for the selected material are particularly important for gas separation application using nano-porous inorganic membranes. Selecting a material that exhibits higher adsorption of a gas relative to another gas using certain membrane material can be useful in separating the mixture of the two binary gas species. When gas molecules are adsorbed and mobile preferentially on the pore wall, they will diffuse along the pore wall in the direction of decreasing driving forces. If the pore wall of the membrane has an affinity for the gas molecules, a substantial amount of the molecules could be diffused in this manner. Platinum and palladium, for instance, are known to exhibit preferential adsorption to hydrogen [4]. Using these metal species in the membrane could help improve the selectivity of binary mixture of gas containing hydrogen component. Pd impregnated membrane was used [11] and resulted in separation factor between 4 to 8 as illustrated in Table 1 at relatively low pressure application (0.03-0.21 bar). In the absence of this metal, the separation was lower even at relatively higher operating pressures [11-15].

Improvement in the selectivity can be realized if higher pressure is applied. This is due to the degree of the surface diffusion and adsorption contribution towards the permeability increase relies heavily on the pressure (for a given isotherm). The higher the pressure for a given isotherm, the more readily the gas molecules to be adsorbed and mobile along the pore surface of the membranes. The pressure-separation factor relationship will be articulated further in the ensuing topic.

BET surface area, a physical characteristic of membranes, defines how much gas can be adsorbed or accommodated per gram of the material. Higher surface area is preferred since it is the indication of the greater amount of gas that can be adsorbed onto the membrane's pore surface. Higher BET surface area commonly is correlated reciprocally with smaller average pore radii $[16,17]$. The smaller the pore, the greater the separation factor. An infinite $\mathrm{He} / \mathrm{CO}_{2}$ separation factor (100 percent separation) could be obtained if membrane having pore radius less than 4 Angstroms $\left(4 \times 10^{-10} \mathrm{~m}\right)$ or extremely small pores comparable to the size of gas molecules was used [18]. Silica hollow fiber membrane, as illustrated in Table 1, demonstrated the highest separation factor for $\mathrm{H}_{2} / \mathrm{N}_{2}$ mixture [13], and this is attributed to high BET surface area. For nano-porous inorganic membrane, the typical BET surface area is in the range between 200 to $400 \mathrm{~m}^{2} / \mathrm{g}$ [16]. BET surface area as much as $4000 \mathrm{~m}^{2} / \mathrm{g}$ was also observed for zeolitic materials [32].

\subsection{Porosity, Pore Size and Pore Size Distribution}

Porosity is an important parameter that characterizes inorganic materials and differs them from dense membranes. The porosity values could be determined conveniently if micro pore volume and density of the membrane are known [19]. Inorganic structures having high porosity value enable more gases to permeate through since porosity correlates proportionally with permeability. However, highly porous structures may not be able to achieve the desired selectivity of the gases. 
Table 1: Comparison of hydrogen separation factor from different works.

\begin{tabular}{|c|c|c|c|c|c|}
\hline $\begin{array}{c}\text { Mixture } \\
\text { (Knudsen S.F) }\end{array}$ & $\begin{array}{l}\text { Material and } \\
\text { pore size }(\mathrm{nm})\end{array}$ & Preparation technique & Temp. $\left({ }^{\circ} \mathrm{C}\right)$ & Press.(bar) & $\begin{array}{c}\text { Separation } \\
\text { Factor }\end{array}$ \\
\hline & $\mathrm{TiO}_{2}(4)$ & Multi-layer support [12] & $27-29$ & 1.19 & 4.8 \\
\hline $\mathrm{H}_{2} / \mathrm{CO}_{2}$ & $\mathrm{Al}_{2} \mathrm{O}_{3}(4)$ & Pd impregnation [11] & $104-445$ & $0.03-0.21$ & $4.0-8.0$ \\
\hline \multirow[t]{3}{*}{$(4.67)$} & $\mathrm{Al}_{2} \mathrm{O}_{3}(10-20)$ & Anodic alumina [11] & $-196-97$ & $0.23-1.05$ & 5.0 \\
\hline & $\mathrm{SiO}_{2}$ & Hollow fiber [13] & $25-70$ & 21 & $4.7-5.4$ \\
\hline & $\mathrm{TiO}_{2}(4)$ & Multi-layer support [12] & $27-29$ & 1.19 & 2.71 \\
\hline $\mathrm{H}_{2} / \mathrm{CO}$ & $\mathrm{Al}_{2} \mathrm{O}_{3}$ & Multi-layer support [14] & $20-300$ & $1.3-17.4$ & $1.2-2.2$ \\
\hline \multirow[t]{3}{*}{$(3.72)$} & $\mathrm{Al}_{2} \mathrm{O}_{3}(10-20)$ & Anodic alumina [11] & $-196-97$ & $0.23-1.05$ & 3.5 \\
\hline & $\mathrm{SiO}_{2}$ & Hollow fiber [13] & $25-70$ & 21 & $31-62$ \\
\hline & $\mathrm{TiO}_{2}(4)$ & Multi-layer support [12] & $27-29$ & 1.19 & 2.02 \\
\hline $\mathrm{H}_{2} / \mathrm{N}_{2}$ & $\mathrm{Al}_{2} \mathrm{O}_{3}(4)$ & Pd impregnation [11] & $104-445$ & $0.03-0.21$ & $4.0-10.0$ \\
\hline \multirow[t]{2}{*}{$(3.72)$} & Zeolite & In situ synthesis [15] & 20 & 1 & 3.06 \\
\hline & $\mathrm{SiO}_{2}$ & Hollow fiber [13] & $25-70$ & 21 & $125-163$ \\
\hline \multirow[t]{2}{*}{$\mathrm{H}_{2} / \mathrm{SF}_{6}$} & Zeolite-ZSM5 & In situ synthesis [30] & $27-29$ & 1 & 51 \\
\hline & $\begin{array}{c}\mathrm{Al}_{2} \mathrm{O}_{3}(200- \\
600)\end{array}$ & Support [31] & $27-29$ & 1 & 1.12 \\
\hline $\mathrm{H}_{2} / n-\mathrm{C}_{4} \mathrm{H}_{10}$ & $\begin{array}{c}\text { Hydroxy- } \\
\text { sodalite zeolite } \\
(0.28)\end{array}$ & In situ synthesis [31] & $27-29$ & 1 & $>1000$ \\
\hline
\end{tabular}


The choice of porosity values relies heavily on the desired selectivity and on the mechanical strength of the membranes that suit the process application. Highly porous materials are usually associated with lower mechanical strength. Vast number of researches advocated that the effective control over the level of porosity rests on proper selection of sintering temperature profile (to obtain firm coalescence between particles and particles with the support, and a well-determined membrane structure with good mechanical resistance) and binder composition during membrane synthesis. The overall porosity was found to decline with increase in temperature $[1,11,20,29]$. This was due to the micro pore volume that decreased as a result of more of the micro pores evolved and coalesced with other micro pores $(<2 \mathrm{~nm})$ to form meso pores $(2-50 \mathrm{~nm})$ and macro pores $(>50 \mathrm{~nm})$ at higher temperature [16].

Porous inorganic membranes are also frequently characterized in terms of their pore size and pore size distribution. When pore size is comparable to the size of the gas molecules, while other parameters remain constant, the gas permeability across the membrane, to some extent, follows the sequence of diameter of the gas molecules in a decreasing magnitude. Normally, narrow pore size distribution is desired in inorganic membranes for gas separation since wider distribution encompasses unnecessarily large pores. This renders the membranes to be less effective in achieving the desired level of selectivity.

\subsection{Membrane Morphology}

Membrane morphology is another important parameter besides porosity that governs membrane's characteristic. It is commonly performed through SEM micrographs or TEM imaging with certain level of magnification to identify nano-pore structures, in addition to textural details analysis of the top membrane layer. This is to examine the presence of defects forming such as cracks or pinholes and structural deformation. Knowledge of the membrane morphology would be useful if surface modification process would necessitate the subsequent process in order to negate the undesirable defects from developing.

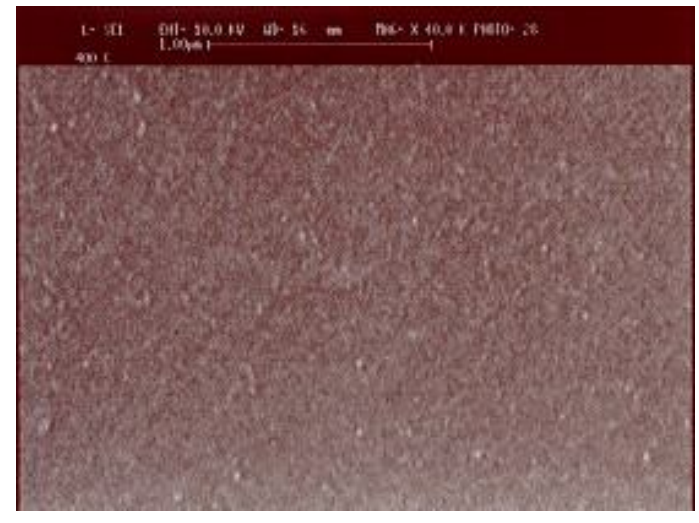

Fig. 1: SEM micrographs of the surface of the sintered alumina membrane (sintered at $400^{\circ} \mathrm{C}$ ) with with $\times 500$ magnification 
In the textural analysis, a hill (observed as a white circle) or crater (observed as a black hole from the opposite side) may be discovered on the photo such as illustrated in Figure 1. This should not be confused with pinholes or cracks, since despite its presence; the hill does not induce structural defection in the membrane. It is not uncommon to develop hills in membrane especially when the surface of the support material (usually petri-dish) contains dust or tiny grains that protrude from the dish surface. The uneven surface eventually contributes to the crater development. In normal procedures, the development of hills or craters is hindered by subsequently coating and firing of the membrane [20].

Membrane samples are not only analyzed from the top and bottom but the crosssectional views as well. The analysis is performed to identify the continuity of the pores, the tortuous path of the membranes and perhaps their nominal lengths. The membrane thickness also could be examined in detail from the analysis such as illustrated in Fig. 2. The answers to many conflicting results and eclectic remarks of membrane performance among researchers employing similar membrane materials and configuration in the past and present studies possibly lie within this analysis.

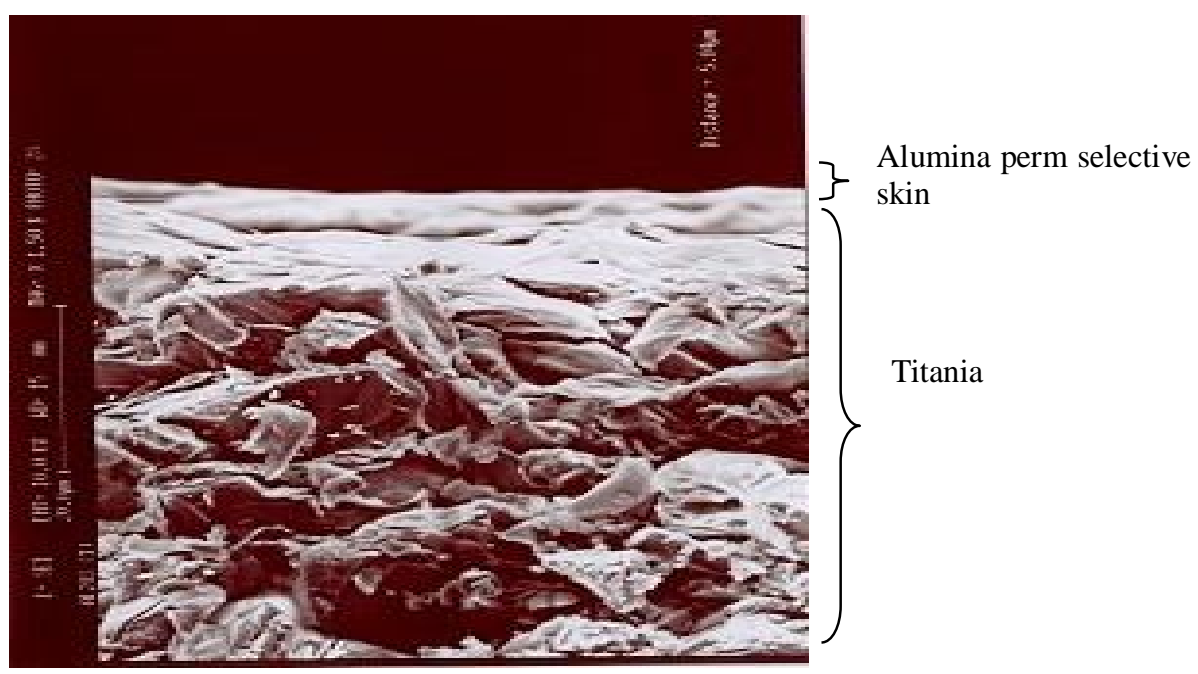

Fig. 2: SEM micrographs of the cross-section of the sintered alumina membrane with $\times 500$ magnification. 


\section{OPERATIONAL PARAMETERS}

\subsection{Feed Rate and Concentration}

Typically, by increasing the feed flow rate and concentration of gas mixtures will result in increase in the permeation of the gases. Separation tends to increase as the concentration of lighter gas species in the feed stream is increased due to the more momentum that the lighter gas species gain from collision between its own molecules rather than the other components molecules [18]. However, the concentration effect on separation is less influential in comparison to the effects of feed pressure and temperature. Unless the gas transport is promoted via adsorption mechanism by selecting a suitable material to enhance the degree of affinity of the gas towards the pore surface, the separation will be strictly confined to the Knudsen separation demonstrated by Knudsen diffusion mechanism such as shown in Fig. 3 [12]. The figure demonstrates that separation tends to approach asymptotically to the respective Knudsen separation factor of the binary gases at relatively high feed concentration.

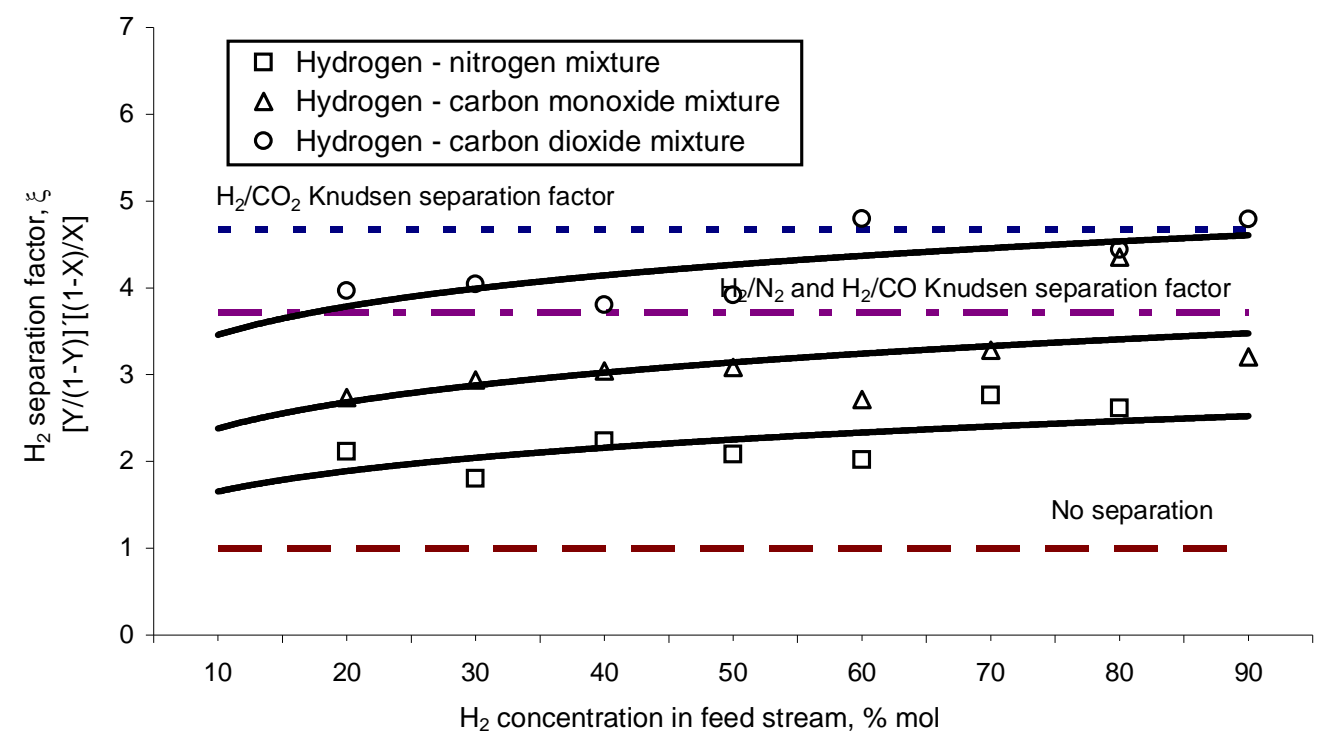

Fig. 3: Hydrogen separation factor as a function of feed concentration at $\mathrm{P}=1.19 \times 10^{6}$

$$
\text { g.cm-1.s-2 (T=301K, rp=2nm, } \varepsilon / \tau=0.385, \theta \text { avg } \approx 0.22) \text { [12]. }
$$

Figure 3 shows the effect of feed concentration on the separation of gas mixture across titania membrane at average pressure of $1.19 \times 10^{6} \mathrm{~g} . \mathrm{cm}^{-1} \cdot \mathrm{s}^{-2}$, temperature $301 \mathrm{~K}$, average pore radius of $2 \mathrm{~nm}$, stage cut $\approx 0.22$ and the ratio of porosity to tortuous factor equivalent to 0.385 . In separation of binary gas mixture, the gas with a lower molecular weight will adsorb faster than the gas with a higher molecular weight. In the study, the $\mathrm{H}_{2}$ gas adsorb faster than other gas component. As the $\mathrm{H}_{2}$ concentration was increased in the feed, the $\mathrm{H}_{2}$ concentration in the permeate stream also increased. The highest increase was for $\mathrm{H}_{2} / \mathrm{CO}_{2}$ mixture followed by $\mathrm{H}_{2} / \mathrm{CO}$ and $\mathrm{H}_{2} / \mathrm{N}_{2}$ mixtures. The dotted lines in the figure represent the Knudsen or ideal separation factor, the ratio of the square root of the higher molecular weight gas to lower molecular weight gas. Separation existed for all the mixtures but 
apparently confined only to the Knudsen separation demonstrated by Knudsen diffusion mechanism. The hydrogen separation factor in $\mathrm{H}_{2} / \mathrm{CO}_{2}$ gas mixture reached the Knudsen separation factor asymptotically at high hydrogen concentration. Similar trend was observed for $\mathrm{H}_{2} / \mathrm{CO}$ and $\mathrm{H}_{2} / \mathrm{N}_{2}$ but to a magnitude lower than the respective ideal separation factor. The solid curves representing the experimental data for the respective mixtures in Fig. 3 are calculated results employing complete mixing model. The curves follow second order exponential.

\subsection{Stage Cut}

Stage cut, defined as the ratio of the total permeate flow rate to the total feed flow rate, is one of the operational factors that remains to be crucial in the field of gas separation using inorganic membranes. In most instances, separation tends to increase with decrease in stage cut as illustrated in Fig. 2 [12].

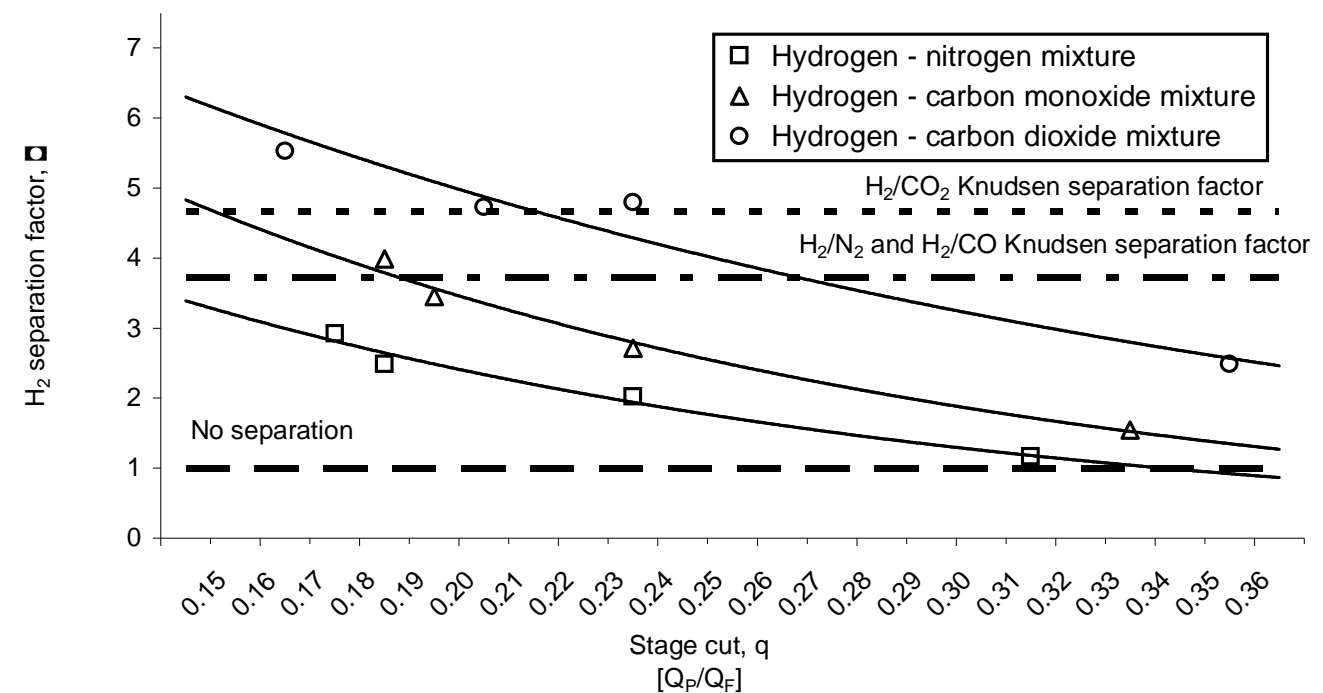

Fig. 4: Hydrogen separation factor as a function of stage cut at $\overline{\mathrm{P}}=1.19 \times 10^{6} \mathrm{~g} \cdot \mathrm{cm}^{-1} \cdot \mathrm{s}^{-2}$ (50/50 mol ratio, $\left.\mathrm{T}=301 \mathrm{~K}, \mathrm{r}_{\mathrm{p}}=2 \mathrm{~nm}, \varepsilon / \tau=0.385\right)$ [12].

Figure 4 shows the hydrogen separation factor as a function of stage cut. The concentration in the inlet stream was maintained at $50 \mathrm{~mol}$ percent of hydrogen and 50 mol percent of the other component. The permeate flow rate varied in the range between 15 to $31 \mathrm{ml} / \mathrm{min}$ corresponding to the total feed flow rate increase from 50 to $200 \mathrm{ml} / \mathrm{min}$, respectively. Stage cut, $\theta$, in the experiment was decreased by increasing the feed flow rate. As the feed flow rate was increased (and thereby $\theta$ decreased), the separation factor increased and to a certain extend went beyond the boundary of Knudsen separation factor.

The influence of stage cut on the separation is governed by the molecular diffusion and driving force. At high feed flow rate (lower stage cut), the lighter permeating component from the mixture diffuses into the permeate stream faster due to the greater difference in concentration between feed and permeate stream. 


\subsection{Pressure}

The influence of pressure on the permeation rate of the more diffusive gas has been widely acknowledged in the past and present work [1-32]. At relatively low pressure, separation is normally confined to Knudsen separation contributed by Knudsen diffusion mechanism $[12,21]$. However, by increasing pressure substantially, separation of gases can exceed the boundary of Knudsen separation factor, and at the onset, shift towards the desired level due to the presence of surface diffusion mechanism [12] as illustrated in Fig. 5. Essentially, the separation can be further increased if the preferential adsorption for particular gas is aided with proper material selection and this has been discussed under section 2.1 (membrane material and surface area).

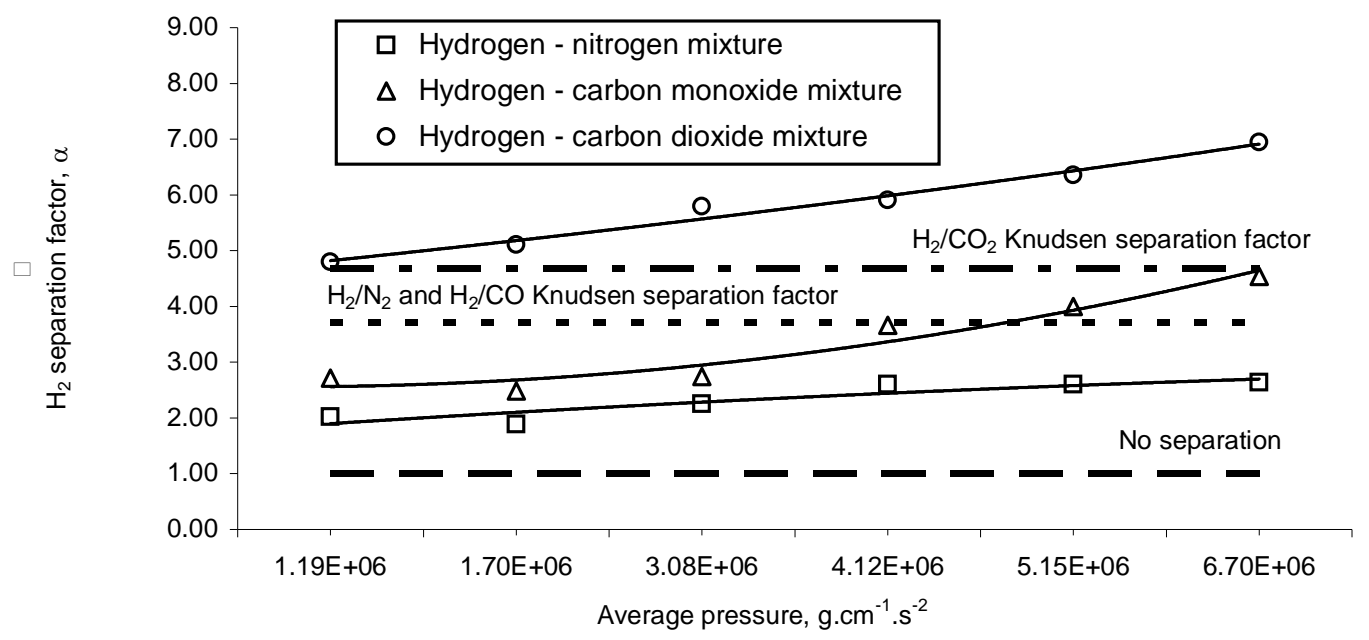

Fig. 5: Hydrogen separation factor as a function of average pressure (50/50 mol ratio, $\mathrm{T}=301 \mathrm{~K}, \mathrm{rp}=2 \mathrm{~nm}, \varepsilon / \tau=0.385$, $\theta$ avg $\approx 0.22$ ) [12].

An experiment was conducted to investigate the influence of average pressure on the separation of gases [12], during which, the temperature was maintained at $301 \mathrm{~K}$, average pore radius of $2 \mathrm{~nm}$, stage cut $\approx 0.22$ and the ratio of porosity to tortuous factor equivalent to 0.385 were selected. The results of this work are shown in Fig. 3. The figure shows that as average pressure was increased the separation factor increased beyond the Knudsen separation factor for $\mathrm{H}_{2} / \mathrm{CO}_{2}$ mixture and $\mathrm{H}_{2} / \mathrm{CO}$ mixture to certain extend. For $\mathrm{H}_{2} / \mathrm{N}_{2}$ mixture, the observed separation factor reached approximately to Knudsen separation factor at high average pressure. This demonstrates that at higher average pressure, hydrogen in $\mathrm{H}_{2} / \mathrm{CO}_{2}$ mixture and $\mathrm{H}_{2} / \mathrm{CO}$ to some extend no longer confined in the Knudsen diffusion region. Another mechanism started to prevail and apparently, that was the surface diffusion mechanism. Essentially, the increase of separation factor at high pressure was dominated by the surface adsorption and the preferential adsorption for $\mathrm{H}_{2}$ by the membrane was actually higher than that of the other component gases, allowing more of $\mathrm{H}_{2}$ being adsorbed and mobile along the pore wall. 


\subsection{Temperature}

Other things remain equal, gas permeation has been known to vary inversely with the square root of temperature and that surface diffusion contributed minimally to gas permeation rate at a high temperature process. Since adsorption mechanism is less promising at high temperature, the relative permeability reduction for component gas species should be significant enough in order to achieve higher separation of gases. This can be realized by making the pore size of membrane to be used in high temperature process even smaller or creating the tortuous path longer to prevent the less diffusive gas from permeating into the membrane readily [12].

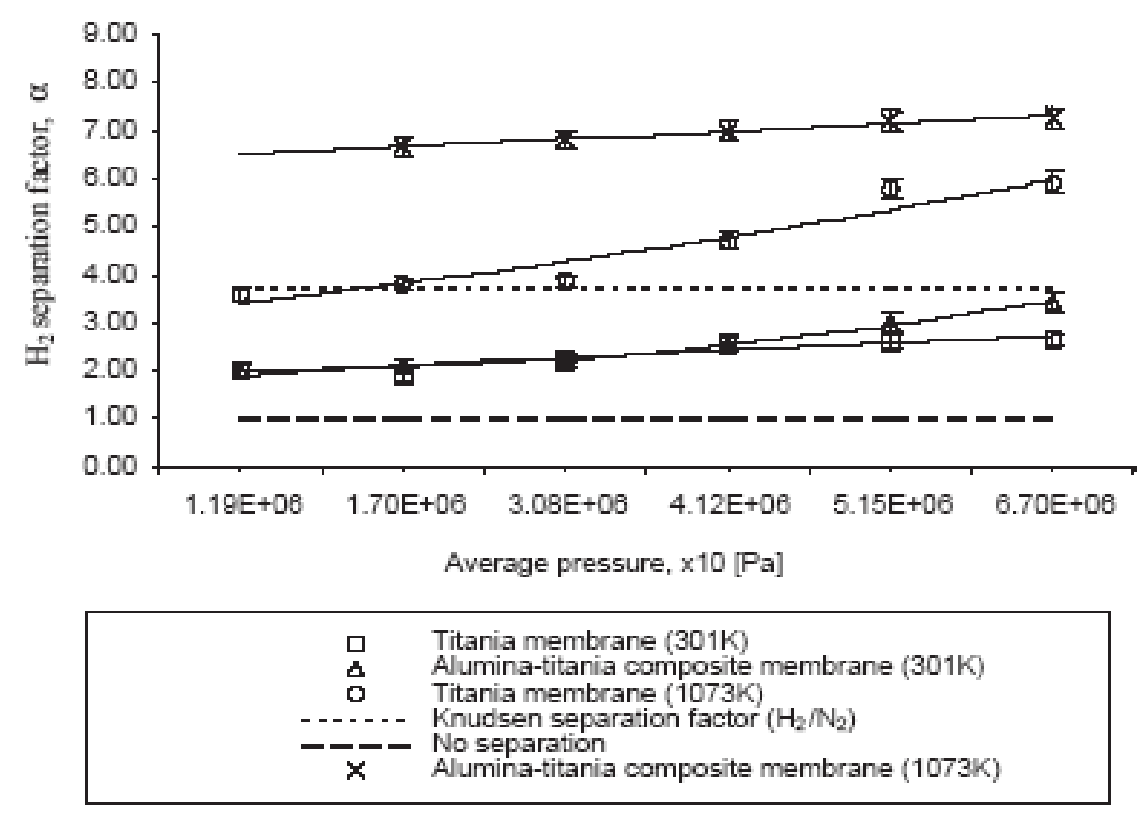

Fig. 6: Separation factor of $\mathrm{H}_{2} / \mathrm{N}_{2}$ in commercial titania and modified titania (alumina +titania) membrane at low and high temperature respectively [21].

Figure 6 illustrates separation factor for $\mathrm{H}_{2} / \mathrm{N}_{2}$ across titania and modified titania membrane at low and high temperature respectively [21]. The perm-selective skin coated on the membrane support (shown in Figure 2) that had reduced pore size was effective in improving the separation of gas mixture containing $\mathrm{H}_{2}$ and $\mathrm{N}_{2}$ even at high operating temperature. The higher separation factor was obtained due to the perm-selective skin that was able to retain pores of smaller than four $\mathrm{nm}$ at higher operating temperature. The higher separation factor was also attributed to the fact that the surface flow of nitrogen diminished at a more distinct magnitude at higher temperature than that of hydrogen, yielding permeability ratio of $\mathrm{H}_{2} / \mathrm{N}_{2}$ (separation factor) at low temperature to be lower than at higher temperature.

\section{GAS MOLECULAR CHARACTERISTICS}

The distinctive characteristics of gas molecules play an important role in permeability of the gases across inorganic membranes $[12,21]$. These molecular characteristics include 
the gas molecular weight, diameter, critical temperature, critical pressure, molecular interaction (binding energy), Lennard-Jones parameters and diffusion volumes. Defying the importance of these factors in gas separation application would limit the effectiveness of the membranes and their performance. Examples of these characteristic values for selected gas species whose diameters are reported $[13,18]$ can be viewed from Table 2.

Table 2: Gas molecular properties.

\begin{tabular}{cccccccc}
\hline Gas & \multicolumn{2}{c}{ Molecular Diameter } & $\mathrm{T}_{\mathrm{c}}$ & $\begin{array}{r}\mathrm{P}_{\mathrm{c}} \\
(\mathrm{atm})\end{array}$ & $\begin{array}{c}\mathrm{M} \\
(\mathrm{g} / \mathrm{mol})\end{array}$ & \multicolumn{2}{c}{$\begin{array}{c}\text { Lennard-Jones } \\
\text { Parameters }\end{array}$} \\
\hline & {$[18]$} & {$[13]$} & & & & $\sigma(\AA)$ & $\varepsilon / \mathrm{k}(\mathrm{K})$ \\
\hline $\mathrm{H}_{2}$ & 2.968 & 2.89 & 33.3 & 12.8 & 2.016 & 2.915 & 38 \\
$\mathrm{He}$ & 2.576 & 2.6 & 5.26 & 2.26 & 4.003 & 2.576 & 10.2 \\
$\mathrm{CH}_{4}$ & 3.88 & - & 190.7 & 45.8 & 16.04 & 3.822 & 137 \\
$\mathrm{CO}$ & 3.590 & 3.76 & 133 & 34.5 & 28.01 & 3.590 & 110 \\
$\mathrm{~N}_{2}$ & 3.681 & 3.64 & 126.2 & 33.5 & 28.02 & 3.681 & 91.5 \\
$\mathrm{O}_{2}$ & - & - & 154.4 & 49.7 & 32.0 & 3.433 & 113 \\
$\mathrm{CO}_{2}$ & 3.996 & 3.3 & 304.2 & 72.9 & 44.01 & 3.996 & 190 \\
\hline
\end{tabular}

The molecular interaction in the form of energy interaction between gas-gas molecules and gas-solid interface has been incorporated in a single dimensionless permeability equation [22]. Lennard-Jones parameters, when employed in an empirical formula [23] and diffusion volumes, used in the derived equation [24] could be a useful combination for analyzing gas viscosity at various temperatures and diffusivity estimation in the permeability studies. However, since gas viscosity has less effect on nano-porous membranes, more focus is dedicated towards the diffusivity of gases. Permeability of gases across nano-porous inorganic membranes has been known to increase with increase in gas diffusivity. Since $\mathrm{H}_{2}$ is much more diffusive than $\mathrm{CO}_{2}$ in comparison to $\mathrm{H}_{2}$ and $\mathrm{N}_{2}$, and $\mathrm{H}_{2}$ and $\mathrm{CO}$, the former species retains in permeate stream much longer as demonstrated in Fig. 5 [21] hence, higher concentration in the stream.

\section{ADDITIONAL PARAMETERS}

All the various characteristic factors discussed earlier could be generalized to form a common ground for researchers in acquiring understanding of the microscopic nature and performance aspects of inorganic membranes. However, since accuracy and precision are becoming increasingly imperative, and the fact that the application of inorganic membranes is becoming more pervasive, there is a need to expand the knowledge of material characterization within the context discussed above. 


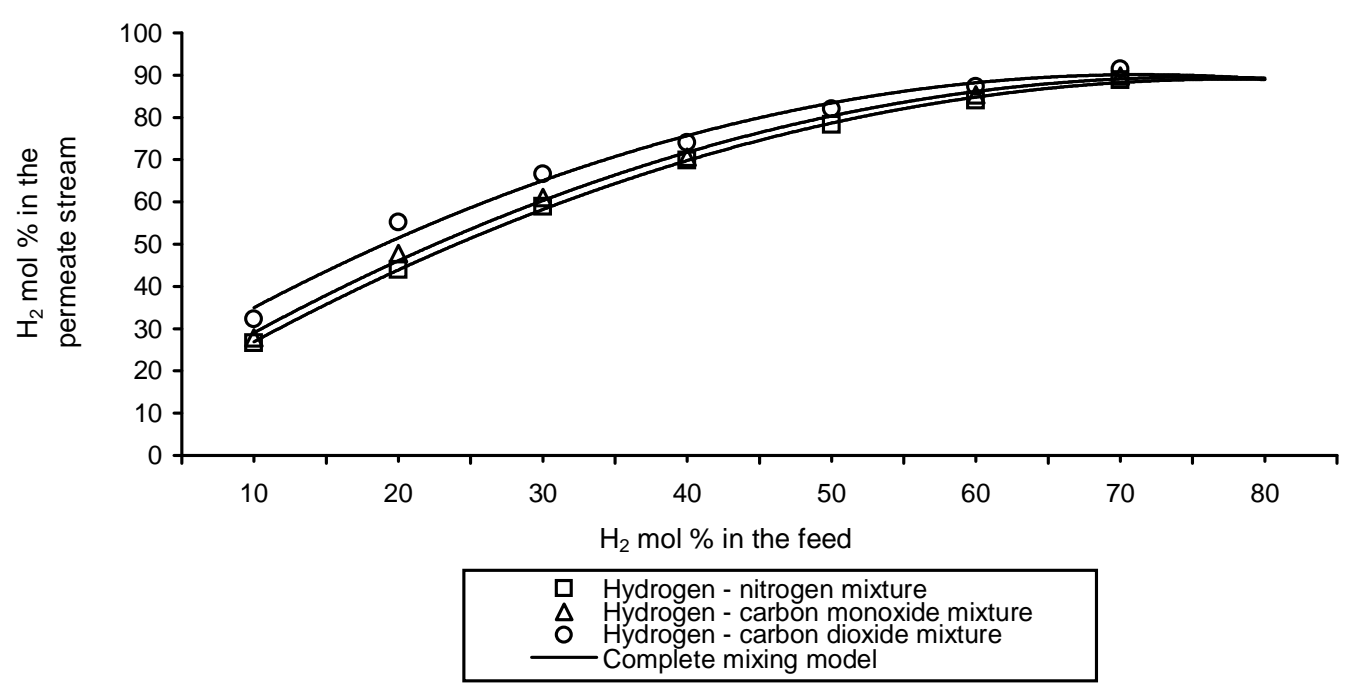

Fig. 5: Effect of feed concentration on permeation of hydrogen across titania membrane at $\overline{\mathrm{P}}=1.19 \times 10^{6} \mathrm{~g} \cdot \mathrm{cm}^{-1} \cdot \mathrm{s}^{-2}\left(50 / 50 \mathrm{~mol}\right.$ ratio, $\mathrm{T}=1073 \mathrm{~K}, \mathrm{r}_{\mathrm{p}}=2.5 \mathrm{~nm}, \varepsilon / \tau=0.385, \theta$ average $\approx$ $0.22)[21]$.

The current techniques of material characterization may not be adequate. This is further exacerbated by the fact that the micro-porous media may not be homogeneous. Within the media there may exist variations in the gas velocities within a pore, between pores of slightly different sizes (diameter and length), and different tortuous paths that have slightly different lengths. An alternative method in describing this heterogeneity is to apply stochastic techniques. A stochastic model is an approach to use the stochastic functions such as arithmetic or geometric mean, standard deviation, variance, and correlation length to generate spatially correlated parameters. Another alternatively innovative approach is to describe the heterogeneities utilizing fractal geometry. Fractal geometry suggests that at the molecular size range, the surfaces of most materials are fractals. The fractal approach relies on the concept of self-similarity and is an alternative way to characterize complex geometries such as the surface area or pore structure of materials. The term "surface fractal" has been used to identify the fractal dimension, $D$. A higher $D$ value suggests a greater wiggle and space filling surface and that the surface is extremely irregular.

In the work of Wei and Wang [25], they investigated pore surface roughness change in composite $\mathrm{Al}_{2} \mathrm{O}_{3}-\mathrm{SiO}_{2}$ membranes by the analysis of surface fractal dimension. Fractal features were analyzed from $\mathrm{N}_{2}$ adsorption-desorption measurements. It was found that surface fractal dimension increased with increase of $\mathrm{SiO}_{2}$ content in composite membrane with different molar ratio of alumina to silica sintered at $600^{\circ} \mathrm{C}$. The surface fractal dimension of membrane with $40 \mathrm{~mol} \%$ silica content increased slightly at sintering temperature of 200 and $600^{\circ} \mathrm{C}$ but decreased at the temperature of $800^{\circ} \mathrm{C}$. This was explained by the viscous mechanism and shrinkages/expands of mass fractal dimension of silica clusters at varying temperature

Huang et al. [26] reported a study on the pore microstructures in two viscous rayonbased activated carbon fiber samples by using nitrogen adsorption and extracted image of HRTEM. One sample exhibited BET surface area of $640 \mathrm{~m}^{2} / \mathrm{g}$ and another $1680 \mathrm{~m}^{2} / \mathrm{g}$. The 
surface fractal dimensions, $D$ of the samples were evaluated by using both nitrogen adsorption and TEM image analysis [27-29].

In fractal geometry, a fractal dimension is used to explain the length scale or roughness of the flow paths measured in the laboratory. Fractal geometry offers a model to explain distinct behavior or patterns at different length scale of irregular objects. Data on this will be collated in the future publication.

\section{CONCLUSION}

Fundamental parameters affecting gas permeation in nano-porous inorganic membranes are discussed. The solitary objective is in the emphasis of the crucial factors in membrane characterization concepts in general, from the past and present experience. These factors are grouped into three categories. The first category is the membrane physical characteristics, which include membrane materials and surface area, porosity, pore size and pore size distribution and membrane morphology. The second category is the operational parameters, which include feed flow rate and concentration, stage cut, temperature and pressure. The third category is the gas molecular characteristics, which include gas molecular weight, diameter, critical temperature, critical pressure, LennardJones parameters and diffusion volumes. Supplementary characterization technique may be needed to gain deeper understanding about the heterogeneity of porous inorganic structures. Alternatively, a method that has the potential to be incorporated in the future will be to apply a stochastic model and fractal dimension to explain distinct behavioral patterns of membrane architectures.

\section{ACKNOWLEDGEMENT}

This paper summarizes the results of work from research grant provided by USM and numbers of colleagues. The author also acknowledges contribution made by Norzeeha Mat Rashid and Nor Faeqah Idrus towards the completion of this article.

\section{REFERENCES}

[1] Lee, D., Zheng, L., Ogama, S.T., Nin, S. and Sarac, R.F. (2004). Synthesis, Characterization and Gas Permeation Properties of A Hydrogen Permeable Silica Membrane Supported on Porous Alumina. Journal Membrane of Science, 231, 117-126.

[2] Bottino, A., Capannelli, G., D'Asti, V. and Piaggio, P. (2001). Preparation and Properties of Novel Organic-Inorganic Porous Membranes. Separation and Purification Technology, 2223, 269-275.

[3] Boechetta, P.,Chiavarotti, G., Masi, R., Sunseri, C. and Di Quarto, F. (2004). Nanoporous Alumina Membranes Filled with Solid Acid for Thin Film Fuel Cells at Intermediate Temperatures. Short Communication, Electrochemistry Communications, 16, 923-928.

[4] Howard, B.H., Killmeyer, R.P., Rothenberger, K.S., Cugini, A.V., Morreale, Enick, R.M. and Bustamante, F. (2004). Hydrogen Permeance of Palladium-Copper Alloy Membranes Over a Wide Range of Temperature and Pressures. Journal of Membrane Science, 241, 207218. 
[5] Venkataraman, V.K., Rath, L.K. \& Stern, S.A. (1991). Potential Application of Micro-porous Inorganic Membranes to The Separation of Industrial Gas Mixtures. Key Engineering Materials, 62, 347-352

[6] Zaman, J. and Chakma, A. (1994). Inorganic membrane reactors. Journal of Material Science, 92, 1-28

[7] Uhlhorn, R.J.R., Keizer, K. \& Burggraaf, A.J. (1989). Gas and Surface Diffusion in Modified $\gamma$-alumina Systems. Journal of Membrane Science, 46, 225-241

[8] Uhlhorn, R.J.R., Huis Int'l Veld, M.H.B.J., Keizer, K. \& Burggraaf, A.J. (1989). High Permselectivities of Microporous Silica Modified $\gamma$-alumina Membrane. Journal of Material Science, 8, 1135-1138

[9] Van Veen, H.M., Tol, J.P.B.M., Engelen, C.W.R. \& Veringa, H.J. (1991). High Temperature Gas Separation with Alumina Membranes. Key Engineering Materials, 62, 593-598

[10] Kusakabe, K., Yamaki, T., Maeda, H. \& Morooka S. (1993). Porous $\gamma$-alumina Membrane Modified with Ultrafine Zirconia Particle Prepared by Reversed Micelles Method. American Ceramic Society, 38, 1-18

[11] Hsieh H.P. (1996). Inorganic membrane for separation and reaction. Membrane Science and Technology Series, 3. New York: Elsevier Publication. p. 28-71,242, 249-251

[12] Othman, M.R., Mukhtar, H. and Ahmad, A.L. Permeation of $\mathrm{H}_{2}$ Across Titania and Modified Titania Membranes at Low Temperature Region. $15^{\text {th }}$ Symposium of Malaysian Chemical Engineers SOMChe 2001. 11-12 September 2001, Johor Bharu. Proceedings p. 121-126.

[13] Way, J.D. and Roberts, D.L. (1992). Hollow Fiber Inorganic Membranes for Gas Separations. Separation. Science and Technology, 27, 29-41

[14] Wu, J.C.S, Flowers, D.F. \& Liu, P.K.T. (1993). High Temperature Separation of Binary Gas Mixtures Using Microporous Ceramic Membranes. Journal of Membrane Science, 77, 85-98

[15] Jia, M.D., Peinemann, K. \& Behling, R. (1993). Ceramic Zeolite Composite Membranes: Preparation, Characterization, and Gas Permeation. Journal of Membrane Science, 82, 15-26

[16] M.R. Othman, H. Mukhtar and A.L. Ahmad. (2001). Characteristics of Unsupported Alumina Membrane Prepared Using Sol-Gel Technique. ASEAN Journal on Science and Technology for Development. Vol. 18 no. 2, 59-70

[17] A.F.M.Leenaars, K.Keizer, A.J.Burggraaf. (1984).The preparation and characterization of alumina membranes with ultra-fine pores. Journal of Material Science. 19, 1077-1088

[18] D.E Fain and G.E Roettger .(1993). Coal gas cleaning and purification with inorganic membranes. Journal of Engineering for Gas Turbines and Power. vol.115, 631-638

[19] De Lange R.S.A., Hekkink, J.H.A, Keizer, K. \& Burggraaf, A.J. (1996). Microstructural Properties of Non-supported Microporous Ceramic Membrane Top Layers Obtained by the Sol Gel Process. Journal of Non-Crystalline Solids, 195, 203-221

[20] Othman, M.R., Mukhtar, H. Review on Development of Ceramic Membrane From Sol-Gel Route: Parameters Affecting Characteristics of the Membrane. IIUM Engineering Journal, 2000, Vol. 1, no. 2, p. 29-34.

[21] Ahmad, A.L. Othman, M.R., and Mukhtar, H. (2004). $\mathrm{H}_{2}$ Separation from Binary Gas Mixture Using Coated Alumina-Titania Membrane by Sol Gel Technique at High Temperature Region. International Journal of Hydrogen Energy, 29, 817-828. 
[22] Shindo, Y., Hakuta, T., Yashitome, H. \& Inoue, H. (1983). A Dimensionless Equation for Gas Diffusion in Microporous Media in Knudsen's Regime. Journal of Chemical Engineering Japan, 16, 521-523

[23] Bird R.B., Stewart, W.E. \& Lightfoot, E.N. (2002). Transport Phenomena, 4th ed. New York: John Wiley \& Son. 744-755

[24] Geankoplis, C.J. (1993). Transport process and unit operations, 3rd ed. p. 759-760. Prentice Hall

[25] Wei, Qi and Wang, D. (2003). Pore Surface Fractal Dimension of Sol-Gel-Derived $\mathrm{Al}_{2} \mathrm{O}_{3}-$ $\mathrm{SiO}_{2}$ Membranes. Materials Letters, 57, 2015-2020.

[26] Huang Zheng-Hong, Feiyu Kang, Wen Lai Huang, Jun-Bing Yang, Kai-Ming Liang, MengLong Cui, Zhiying Cheng. (2002). Pore structure and fractal characteristics of activated carbons fibers characterized by using HRTEM. Journal of Colloid and Interface Science, 249, 453-457.

[27] Carpinteri, A. and Spagnoli, A. (2004). A Fractal Analysis of Size Effect on Fatigue Crack Growth. International Journal of Fatigue, 26, 125-133.

[28] Wang, Y. and Xu, K.-W. (2004). Characterization of Surface Morphology of Copper Tungsten Thin Films by Surface Fractal Geometry and Resistivity. Thin Solid Films, 468, 310-315.

[29] S.Benfer, U.Popp, H.Richter, C.Siewert, G.Tomandl. (2001). Development and Characterization of Ceramic Nanofiltration Membranes. Separation and Purification Technology. 22-23, 231-237.

[30] H. Richter, I. Voigt, G. Fischer and P. Puhlfürß (2003). Preparation of zeolite membranes on the inner surface of ceramic tubes and capillaries. Separation and Purification Technology, Volume 32, Issues 1-3, Pages 133-138.

[31] Xiaochun Xu, Yun Bao, Chunshan Song, Weishen Yang, Jie Liu and Liwu Lin (2004) Microwave-assisted hydrothermal synthesis of hydroxy-sodalite zeolite membrane. Microporous and Mesoporous Materials, Volume 75, Issue 3, Pages 173-181

[32] Koichi Matsuoka, Yasushi Yamagishi, Toshiaki Yamazaki, Norihiko Setoyama, Akira Tomita and Takashi Kyotani (2004). Extremely high microporosity and sharp pore size distribution of a large surface area carbon prepared in the nanochannels of zeolite Y. Short communication. Carbon. In Press, Corrected Proof.

\section{Nomenclature}

$D_{s}$ surface diffusion $\left[\mathrm{m}^{2} \cdot \mathrm{s}^{-1}\right]$

$f \quad$ equilibrium loading factor [mol. $\mathrm{kg}^{-1}$ ]

$K$ permeability $\left[\mathrm{mol} \cdot \mathrm{s}^{-1}\right][\mathrm{m}]\left[\mathrm{m}^{-2}\right]\left[\mathrm{kg}^{-1} \cdot \mathrm{m} \cdot \mathrm{s}^{2}\right]$

$\bar{P}$ average pressure in membrane pore $\left[\mathrm{kg} \cdot \mathrm{m}^{-1} \cdot \mathrm{s}^{-2}\right]$

$M$ mass of molecule [kg.kgmol ${ }^{-1}$ ]

$R \quad$ gas constant $\left[\mathrm{kg} \cdot \mathrm{m}^{2} \mathrm{~s}^{-2} \cdot \mathrm{kgmol}^{-1} \cdot \mathrm{K}^{-1}\right]$

$r_{g} \quad$ radius of gas molecule [m]

$r_{p}$ radius of membrane pore [m] 
$T$ temperatue $[\mathrm{K}]$

$z \quad$ compressible factor [-]

\section{Greek letters}

$\tau$ tortuosity factor [-]

$\mu \quad$ viscosity of gas $\left[\mathrm{kg} \cdot \mathrm{m}^{-1} \cdot \mathrm{s}^{-1}\right]$

$\varepsilon$ porosity [-]

$\rho_{m}$ density of membrane $\left[\mathrm{kg} \cdot \mathrm{m}^{-3}\right]$

\section{BIOGRAPHIES}

Mohd Roslee Othman currently is a lecturer, Chairman of Separation Process and Catalysis Program and Industrial Training Coordinator of School of Chemical Engineering, Universiti Sains Malaysia (USM). He obtained his Bachelor and Master of Science Degree in Petroleum Engineering from University of Missouri-Rolla, USA in 1994 and 1997 respectively, before completing his Ph.D. Degree in Chemical Engineering from USM in 2002. His research areas include inorganic membrane development for gas separation, gas adsorption, permeability of fluid in porous media and reservoir study.

Hilmi Mukhtar currently is a senior lecturer and the Head of Chemical Engineering Program, Universiti Teknologi Petronas (UTP). His research area is in membrane technology.

Abdul Latif Ahmad currently is a Associate Professor of Chemical Engineering, Engineering Campus, Universiti Sains Malaysia (USM). He received his BSc., MSc. and $\mathrm{PhD}$. in Chemical Engineering from Wales, UK. His research area is in membrane technology. 